\title{
AS REPRESENTAÇÕES SOCIAIS NA ARTICULAÇÃO DA UNIVERSIDADE-ESCOLAS-PODER PÚBLICO- -SOCIEDADE - RESULTADOS PRELIMINARES DE UM ESTUDO ETNOGRÁFICO
}

\author{
THE SOCIAL REPRESENTATIONS IN THE ARTICULATION \\ OF THE UNIVERSITY-SCHOOLS-PUBLIC POWER-SOCIETY - \\ PRELIMINARY RESULTS OF AN ETHNOGRAPHIC STUDY
}

LAS REPRESENTACIONES SOCIALES EN LA ARTICULACIÓN DE LA UNIVERSIDAD-ESCUELAS-PODER PÚBLICO-SOCIEDAD RESULTADOS PRELIMINARES DE UN ESTUDIO ETNOGRÁFICO

Eliane de Souza Cruz ${ }^{1}$ Giovano CANDIANI ${ }^{2}$

JoAQUim BERNARDinO LOPES ${ }^{3}$ Nilza Maria Vilhena Nunes da Costa ${ }^{4}$ Alcina Maria Testa Braz da Silva ${ }^{5}$ Glória Regina Pessôa Campello Queiroz ${ }^{6}$ ${ }^{1}$ Professora Doutora na Universidade Federal de São Paulo (UNIFESP). Diadema/SP- Brasil. ${ }^{2}$ Professora Doutora na Universidade Federal de São Paulo (UNIFESP). Diadema/SP- Brasil ${ }^{3}$ Universidade de Trás-os-Montes e Alto Douro (UTAD). Portugal ${ }^{4}$ Universidade de Aveiro. Portugal

${ }^{5}$ Centro Federal de Educação Tecnológica Celso Suckow da Fonseca (CEFET). Rio de Janeiro - Brasil

${ }^{6}$ Professora Doutora na Universidade do Estado do Rio de Janeiro (UERJ). Rio de Janeiro - Brasil.

Resumo Apresentam os resultados preliminares da pesquisa etnográfica realizada no âmbito do programa de extensão Articul@ções desenvolvido no âmbito da Educação em Ciências e Formação de Professores de Ciências que possui quatro projetos, a saber: i) articula eventos; ii) articula escolas; iii) articula formação e iv) articula cursinhos populares. 
Pretende-se compreender as representações sociais da articulação da universidade-escolas-poder público-sociedade das ações e discursos nos diferentes contextos. Os agentes externos são vistos como manipuladores; participante ativo, passivo ou estratégico. Os discursos revelam quer a valorização do contributo da pesquisa pelos práticos, quer a valorização do contributo dos práticos na formação dos professores. Entretanto, há receio de desvio da função dos pesquisadores e estagiários no contexto escolar e dificuldade em se romper relações hierárquicas entre pesquisadores e práticos no contexto universitário.

Palavras-chave: Articulação pesquisa-prática; Escolas; RepresentaÇões sociais; EtnoGRAFIA.

ABstract The preliminary results of the ethnographic, research carried out under the Articul@tions extension program developed in the scope of Science Education and Science Teacher Training, are presented, which has four projects, namely: i) articula events; ii) articula schools; iii) articula training and iv) articula popular courses. It is intended to understand the social representations of the articulation of the university-schools-power public-society of the actions and discourses in the different contexts. External agents are seen as manipulators; active, passive or strategic participant. The discourses reveal both the appreciation of the contribution of research by practitioners and the appreciation of the contribution of practitioners in the training of teachers. However, there is fear of deviation of the function of researchers and trainees in the school context and difficulty in breaking hierarchical relationships between researchers and practitioners in the university context.

KEY-WORDS: ARTICULATION RESEARCH-PRACTICE; SCHOOLS; SOCIAL REPRESENTATIONS; ETHNOGRAPHY.

Resumen Se presentan los resultados preliminares de la investigación etnográfica realizada en el marco del programa de extensión Articul@s desarrollado en el ámbito de la Educación en Ciencias y Formación de Profesores de Ciencias que tiene cuatro proyectos, a saber: (i) articula eventos; (ii) articula escuelas; (iii) articula formación y (iv) articula cursillos populares. Se pretende comprender las representaciones sociales de la articulación de la universidad-escuelas-poder público-sociedad de las acciones y discursos en los diferentes contextos. Los agentes externos son vistos como manipuladores; participante activo, pasivo o estratégico. Los discursos revelan tanto la valorización de la contribución de la investigación por los prácticos, o la valorización de la contribución de los prácticos en la formación de los profesores. Sin embargo, hay temor de desvío de la función de los investigadores y pasantes en el contexto escolar y dificultad en romper relaciones jerárquicas entre investigadores y prácticos en el contexto universitario.

Palabras Clave: articulación inVestigación-Práctica; escuelas, Representaciones sociaLES; ETNOGRAFÍA. 


\section{INTRODUÇÃo}

O programa Articul@ções - pesquisa e práticas na Educação Básica e Ensino Superior - surge dos trabalhos já realizados desde 2002 pela nossa equipe luso-brasileira que tem desenvolvido a linha de pesquisa Relação da Pesquisa Educacional - Práticas dos Professores da Educação Básica e do Ensino Superior no âmbito da Educação em Ciências e Formação de Professores de Ciências. O foco centrou-se inicialmente no "impacto da pesquisa nas práticas" (COSTA, 2003). A partir de 2006, o foco passou a ser "articulação da pesquisa e práticas", que inclui necessariamente o impacto/influência mútuo, ou seja, impacto da pesquisa nas práticas e impacto das práticas na pesquisa. Cruz (2012) adaptou o modelo epistemológico de McIntyre (2005), considerando a articulação como um conceito complexo operante em várias dimensões (ontológica, política, metodológica etc.), além da epistemológica (CRUZ, POMBO e COSTA, 2008; CRUZ, LOPES e COSTA, 2015).

Esta linha de pesquisa foi introduzida na Universidade Federal de São Paulo (UNIFESP) - Diadema, em 2014, por meio da indissociabilidade entre ensino, extensão e pesquisa, caracterizada pela integração da ação desenvolvida às formações técnica e cidadã do estudante e pela produção e difusão de novos conhecimentos e novas metodologias. Este grande projeto "guarda-chuva" possui quatro projetos, a saber: i) articula eventos; ii) articula escolas; iii) articula formação e iv) articula cursinhos populares. O fio condutor evidencia-se quer na clareza de diretrizes (articulação do conhecimento acadêmico e conhecimento prático dos mais experientes), quer na interprofissionalidade (aproximação dos agentes da educação básica e ensino superior) voltado para um objetivo comum (aproximação da universidade-escolas-poder público-sociedade). Constitui-se em um programa-conjunto articulado de projetos e ações de extensão, de caráter multidisciplinar (por exemplo, no projeto dos cursinhos preparatórios populares para cursos superiores e técnicos) e interdisciplinar (por exemplo, na educação ambiental), sendo integrado a atividades de pesquisa (por exemplo, produção de conhecimento teórico e metodológico sobre a articulação) e de ensino (por exemplo, inserindo no currículo das unidades curriculares a perspectiva de articulação da pesquisa e prática). Este programa está sendo desenvolvido em duas instituições:

- Universidade Federal de São Paulo (UNIFESP) no CEFE (Centro de Formação de Educadores da Escola Básica) e na estrutura física do LIFE (Laboratório Interdisciplinar de Formação de Educadores);

- Universidade do Estado do Rio de Janeiro (UERJ) no laboratório similar ao LIFE que se chama Laboratório Interdisciplinar Educação em Ciências (LIEC).

Possui as seguintes características:

- Integração no território (Município de Diadema preferencialmente, antes da expansão do programa);

- Grupos populacionais (acadêmicos, práticos e sociedade em geral por meio da parceria/apoio da APEOESP - Associação de Professores do Ensino Oficial do Estado de São Paulo, ADUNIFESP - Associação de Docentes da UNIFESP, Rede 
e Movimento Social Emancipa, Rede Juventude Diadema Ativa, Espaço Cultural Coletivo 217, Associação de Moradores 18 de Agosto, Associação Oeste de Diadema, entre outros). Na sua 4. ${ }^{a}$ vertente articulação de cursinhos populares verifica-se a integração da população historicamente excluída do Ensino Superior composta por alunos com baixa renda, moradores de bairros distantes e egressos de escolas públicas;

- Interinstitucionalidade está presente nas parcerias internacionais e nacionais entre as Universidades Portuguesas - Universidade de Aveiro (UA) e Universidade de Trás-os-Montes e Alto-Douro (UTAD) e as Universidades Brasileiras - Universidade do Estado do Rio de Janeiro/UERJ e Centro Federal de Educação Tecnológica Celso Suckow da Fonseca (CEFET); além de várias instituições, Escolas Públicas Estaduais, Escolas Públicas Municipais, Escola Técnica e Profissional SENAI Manuel Garcia Filho, Escola Particular Monteiro Lobato (EMOL) e Secretaria Municipal de Educação de Diadema.

\section{Problema de investigaÇão}

O objetivo geral do programa de extensão reflete a sua missão que é promover a aproximação/interação entre universidades, escolas e sociedade (comunidade local, movimentos sociais etc.) e o poder público educacional (secretarias municipais, diretorias de ensino, conselhos, fóruns etc.).

Considera-se que as parcerias concretizadas desde 2014 são um terreno fértil para a presente investigação que visa analisar as representações sociais (RS) dos agentes nos quatro segmentos (universidades, escolas, sociedade e poder público educacional) sobre o fenômeno da articulação entre a pesquisa e a prática na Educação Básica e Ensino Superior no geral, e em particular na Educação em Ciências e Formação de Professores de Ciências (áreas de pesquisa da maioria dos pesquisadores da equipe).

A Teoria das Representações Sociais (TRS) foi introduzida pelo sociólogo Serge Moscovici e atualmente é utilizada em diferentes áreas do conhecimento. As ideologias constituem-se âncoras das RS que orientam a formação identitária do grupo em que o sujeito está inserido ou é pertencente, ou seja, aspecto que está localizado no núcleo central das RS. Consideramos as ideologias como manifestação que orienta a conduta e a formação identitária de um grupo determinado, o que pode e o que não pode ser dito, aspecto importante a ser considerado quando estudamos RS. As ideologias, veladas ou não, estão presentes no discurso do sujeito, definindo o lugar de onde fala e como expressa a realidade, ou seja, são o núcleo das RS (SILVA, 2011).

O significado de RS assumido pelo grupo de pesquisa traduz-se nas palavras de Santos (2012, p. 203):

A representação social como guia de interpretação da realidade. Nessa concepção, a representação atua como um guia para a definição e interpretação dos aspectos da realidade, assim como de intervenções nesses aspectos. Em outras 
palavras, a representação é um sistema de interpretação da realidade, filtros que organizam as relações do indivíduo com sua realidade, orientando as práticas sociais. Com elas, capacitamo-nos de uma linguagem comum que permite o intercâmbio simbólico entre os indivíduos.

Segundo Moscovici (2007), as RS constituem uma terceira instância que seria a da fusão dos universos (individuais e sociais/coletivos). ${ }^{1}$ Elas são flexíveis e adaptam-se à identidade de um grupo social, marcando sua diferença e construindo novas identidades culturais (que neste projeto seria a de uma cultura articuladora).

O autor aponta dois processos nas RS: i) objetivação - núcleo central mais estável (representações de referência segundo o autor (PY, 2000 apud SILVA, 2011) - noções abstratas são transformadas em algo concreto e disseminado no discurso, que pode ser comparado e interpretado e ii) ancoragem - núcleo periférico ou representações de uso ou mais instáveis (segundo autor PY, 2000 apud SILVA, 2011) - aquilo em que ancora e nos coloca no quadro da referência do conhecido e familiar. As representações sociais constituem-se, pois, como um quadro de referência conceptual e metodológico dos significados partilhados por todo segmento que circula através do discurso, orientando práticas e condutas de um grupo. Esse quadro de referência serve, assim, para desenvolver intervenções que se fundamentam nas culturas e práticas sociais.

\section{RelaÇões entre a Pesquisa e as práticas na EducaÇão Básica e Ensino SUPERIOR}

Há diferentes formas de conceber as relações entre a pesquisa e as práticas na Educação Básica e Ensino Superior na literatura nacional e internacional, a saber: a) Impacto das pesquisas educacionais nas práticas; b) Articulação da pesquisa educacional e práticas; e c) Pesquisa educacional sem impacto e sem articulação com as práticas.

Esclarece-se que a pesquisa e as práticas são na Educação Básica e Ensino Superior no geral, e em particular na Educação em Ciências e Formação de Professores de Ciências (áreas de pesquisa da maioria dos pesquisadores da equipe) nos espaços formais e não formais.

Em relação à primeira, a) Impacto das pesquisas educacionais nas práticas, a principal referência que transfere o conceito de impacto para o contexto educacional em geral e, em

\footnotetext{
Segundo Silva (2011, p. 48), as RS podem ser confundidas com o senso comum, a opinião e a crença popular: "Para Moscovici (2007), as RS renovam o senso comum a cada instante na sociedade e criam novos tipos sociais. O senso comum é criado e recriado, principalmente em relação ao conhecimento científico e tecnológico popularizado. A opinião é uma posição que um indivíduo ou uma sociedade adotam em relação a um problema controverso, pressupondo uma ação. Já a crença possibilita às pessoas viverem encarnadas em estruturas específicas, e são adotadas por indivíduos que são parte delas, o que Durkheim (apud MOSCOVICI, 2007, p. 177) vai chamar de estranhas ilusões e práticas compartilhadas por uma comunidade, fundamentais no pensamento simbólico, no deslocamento de observações, nos rituais extremados e nas emoções intensas".
} 
particular, no que concerne o impacto da Pesquisa Educacional, é ancorada no Relatório intitulado "The Impact of Educational Research on Policy and Practice", elaborado em dezembro de 2000, pelo National Educational Research Forum (NERF). ${ }^{2} \mathrm{O}$ termo impacto refere-se à influência ou efeito que a pesquisa educacional exerce na audiência. Nessa definição surge outro aspecto, igualmente importante, que é o de audiência, ou seja, os destinatários privilegiados do impacto da pesquisa educacional que, segundo o mesmo Relatório, contemplam: i) os Professores e as Escolas; ii) os Pesquisadores e as Instituições onde se produzem pesquisa, nomeadamente as de Ensino Superior; iii) os Gestores Políticos, as Políticas Educativas das Instituições e a tutela governamental; iv) os mass media; v) financiadores; e vi) a comunidade em geral.

A b) Articulação da pesquisa educacional e práticas requer a apropriação do conceito de 'articulação' para fins educacionais que aceita o fosso entre a pesquisa e prática pela impossibilidade epistemológica do seu total desaparecimento. Poderíamos dizer que a articulação implica uma relação bilateral entre a Pesquisa Educacional $\leftrightarrow$ Práticas nestas dimensões, traduzida pela influência da Pesquisa/pesquisadores nas Práticas/práticos, mas também das Práticas/práticos na Pesquisa/pesquisadores.

E finalmente a c) Pesquisa educacional sem impacto e sem articulação com as práticas. Esta perspectiva entende que a pesquisa educacional não precisa necessariamente exercer impacto nas práticas e políticas (COSTA, 2003) ou estar articulada com as mesmas. Ou seja, é necessário sermos comedidos nas expectativas da relação da pesquisa educacional nas práticas, corroborando com o "enlightenment model" de Hammersley (1997), sob o risco de termos a sua qualidade prejudicada. A este propósito, destacam-se, por exemplo, as pesquisas sobre o "estado da arte" de uma determinada linha de pesquisa, linhas de pesquisa cujos resultados não se encontram ainda devidamente amadurecidos teórica e empiricamente (COSTA, 2003), ou são pesquisas orientadas pela curiosidade do pesquisador mais do que por um problema prático (NERF, 2000). Esclarece-se ainda que não pretendemos fazer juízos de valor em relação às pesquisas educacionais da Educação Básica e Ensino Superior realizadas pelos docentes da academia e professores das escolas, mas problematizar a questão das relações da pesquisa e práticas para a melhoria contínua da qualidade da Educação em geral.

No que diz respeito à dimensão ontológica da articulação, verifica-se que as comunidades de aprendizagem, constituídas por formadores e formandos (professores e futuros-professores), têm vindo a contribuir para a redução das relações hierárquicas entre os mesmos nos cursos e para um maior envolvimento dos professores das escolas na pesquisa.

A hierarquia frequentemente associada ao prestígio diferenciado de cada carreira e/ ou ao estatuto do pesquisador-formador (dimensão política) apresenta-se como entrave à desejável colaboração entre pesquisadores e professores e afeta a comunicação no contexto formativo (GRAVANI, 2008). Além disso, a relação hierárquica entre os intervenientes acaba por interferir na percepção desses atores sobre a natureza do conhecimento, ou seja,

2 The National Educational Research Forum (NERF) is an independent organisation. Its role is to oversee the development of a coherent strategy for educational research and its use. Disponível em: $\underline{w w w . n e r f-u k . o r g}$. 
o conhecimento científico é visto como superior ao conhecimento gerado na prática (dimensão epistemológica).

\section{Projetos de Extensão, Objetivos (da Extensão versus Pesquisa) e Hipóteses}

No quadro 1 apresentam-se os objetivos específicos dos quatro projetos de extensão e de pesquisa, bem, como algumas hipóteses levantadas no estudo exploratório etnográfico (CRUZ, et al. 2017a e 2017b), a saber:

Quadro 1: Objetivos de pesquisa dos quatro projetos e hipóteses

\begin{tabular}{|c|c|c|c|}
\hline Projetos & Objetivos da extensão & Objetivos da pesquisa & Algumas hipóteses \\
\hline $\begin{array}{l}\text { Articula } \\
\text { eventos }\end{array}$ & $\begin{array}{l}\text { Promover eventos cola- } \\
\text { borativos que valorizem } \\
\text { e potenciem o contri- } \\
\text { buto interinstitucional } \\
\text { (universidade, escolas, } \\
\text { gestão pública e entida- } \\
\text { des sociais) na melhoria } \\
\text { da Educação. }\end{array}$ & $\begin{array}{l}\text { Compreender os mecanismos } \\
\text { de articulação (por exemplo, } \\
\text { os eventos com pautas comuns } \\
\text { que contribuem para a susten- } \\
\text { tabilidade da rede). }\end{array}$ & $\begin{array}{l}\text { Alguns eventos sectários e } \\
\text { concorrentes impedem a arti- } \\
\text { culação. }\end{array}$ \\
\hline $\begin{array}{l}\text { Articula } \\
\text { escolas }\end{array}$ & $\begin{array}{l}\text { Dinamizar projetos } \\
\text { voltados ao estabeleci- } \\
\text { mento de redes entre as } \\
\text { escolas e parcerias das } \\
\text { escolas com a UNIFESP } \\
\text { e a UERJ. }\end{array}$ & $\begin{array}{l}\text { Descrever a partilha de sabe- } \\
\text { res, interação professor da uni- } \\
\text { versidade e professor da escola } \\
\text { de forma a fomentar a forma- } \\
\text { ção de rede de professores-pes- } \\
\text { quisadores nas escolas. }\end{array}$ & $\begin{array}{l}\text { A regulamentação e a cre- } \\
\text { ditação das atividades de } \\
\text { pesquisa e de supervisão para } \\
\text { a progressão na carreira po- } \\
\text { tenciarão a aproximação da } \\
\text { universidade-escola e a cons- } \\
\text { trução de conhecimento nas } \\
\text { escolas em colaboração com } \\
\text { os pesquisadores. }\end{array}$ \\
\hline $\begin{array}{l}\text { Articula } \\
\text { formação }\end{array}$ & $\begin{array}{l}\text { Desenvolver competên- } \\
\text { cias científicas e investi- } \\
\text { gativas nos professores } \\
\text { e gestores das institui- } \\
\text { ções parceiras. }\end{array}$ & $\begin{array}{l}\text { Diagnosticar as necessidades } \\
\text { de formação das escolas e as } \\
\text { contrapartidas necessárias para } \\
\text { a articulação. }\end{array}$ & $\begin{array}{l}\text { Os professores dos cursos } \\
\text { de licenciatura (por ex., } \\
\text { orientadores de estágio da } \\
\text { universidade e de pesquisa) } \\
\text { são importantes agentes ar- } \\
\text { ticuladores da Universidade } \\
\text { e Escola e devem participar, } \\
\text { por exemplo, como formado- } \\
\text { res nas aulas de trabalho pe- } \\
\text { dagógico coletivo (ATPC) de } \\
\text { formação como contrapartida } \\
\text { da supervisão da escola aos } \\
\text { estagiários-licenciandos da } \\
\text { universidade. }\end{array}$ \\
\hline $\begin{array}{l}\text { Articula } \\
\text { cursinhos } \\
\text { populares }\end{array}$ & $\begin{array}{l}\text { Apoiar as diversas ini- } \\
\text { ciativas de cursinhos po- } \\
\text { pulares para que parti- } \\
\text { lhem saberes e recursos } \\
\text { (humanos, financeiros e } \\
\text { materiais) }\end{array}$ & $\begin{array}{l}\text { Descrever o cenário dos cur- } \\
\text { sinhos populares- tendências, } \\
\text { constrangimentos e avanços. }\end{array}$ & $\begin{array}{l}\text { Os cursinhos populares liga- } \\
\text { dos aos movimentos sociais } \\
\text { apresentam a identidade do } \\
\text { movimento social e não das } \\
\text { questões pedagógicas ineren- } \\
\text { tes à educação popular. }\end{array}$ \\
\hline
\end{tabular}

Fonte: Autores (2018). 
Atualmente, somos na UNIFESP 42 articuladores atuando nos quatro projetos e em diferentes contextos. Na UERJ e no CEFET, somos duas professoras universitárias, alunos de iniciação científica, graduandos, mestrandos e doutorandos no convênio URRJ/CEFET. Os princípios que regem a prática da equipe são:

- Conhecimentos/práticas não devem ser hierarquizados (as ações serão decididas de forma democrática e participativa por todos os articuladores independentemente de serem coordenadores, professores, monitores ou tutores);

- Explicitação e transparência dos interesses individuais e coletivos dos parceiros;

- Compromisso na divulgação das instituições, das ações/projetos dos parceiros (com exceção de ações/projetos partidários);

- Procura frequente de objetivos/interesses comuns para a sustentabilidade da rede de articuladores;

- Respeito à diversidade do perfil dos membros: práticas, conhecimentos, exigências das carreiras/profissões (disponibilidade de horários, cobrança por publicação, linguagem, pertencentes à rede pública ou privada; etc.).

\section{Metodologia}

A definição de pesquisa etnográfica adotada pela equipe, ciente das armadilhas da Etnografia em Educação (OLIVEIRA, 2013), consiste na descrição de práticas e saberes de sujeitos e grupos sociais a partir de técnicas como observação participante (pesquisador começa a fazer parte da cultura em estudo) e conversações, desenvolvidas no contexto de uma pesquisa. Pressupõem uma extensa recolha de dados durante um período mais ou menos longo. Mais do que um estudo sobre as pessoas, etnografia significa "aprendendo com as pessoas". O pesquisador deve ter tido uma experiência com outros povos de outras culturas (no nosso caso, experiência de 12 anos nas culturas escolar e acadêmica portuguesa), pois o contraste com outras culturas ajuda a entender melhor o sentido que o grupo estudado atribui às suas experiências. Na etapa de exploração da pesquisa etnográfica foram realizadas as primeiras observações com a finalidade de adquirir maior conhecimento sobre o fenômeno e possibilitar a seleção de aspectos para serem sistematicamente investigados. Permitiram a formulação de uma série de hipóteses que foram sendo modificadas à medida que novos dados são coletados. Importa destacar que neste artigo pretende-se apresentar os resultados preliminares da etapa principal da pesquisa e não entraremos nas especificidades das representações sociais na Educação em Ciências.

O êxito deste tipo de pesquisa depende em grande parte da sensibilidade do pesquisador diante das situações com as quais se depara e da interação que estabelece com a população em estudo. Por intermédio do "tato conquistará o respeito e a confiança das pessoas e definitivamente seus materiais serão mais ricos" (HERSKOVITS, 1963, p. 104). ${ }^{3}$

Para finalizar a questão metodológica, adotamos as representações sociais como abordagem metodológica que tem sido utilizada por membros da equipe há vários anos, por

HERSKOVITS, M.J. Antropologia cultural: o homem e seu trabalho. São Paulo: Mestre Jou, p. 98-108, 1963. 
exemplo, no trabalho sobre concepções alternativas no ensino de Física da autora Braz da Silva (1998). De referir que uma das pesquisadoras está no campo desde setembro/2014, quando iniciou a sua primeira unidade curricular de estágio supervisionado e o processo de aproximação às diferentes culturas/contextos do município de Diadema.

As fontes de dados são: i) acadêmicos (docentes e discentes), ii) professores e alunos das escolas, iii) gestores do poder público educacional e iv) representantes de entidades e associações. Os métodos de coleta de dados são: i) estudo documental do diário de bordo dos articuladores que estão envolvidos na pesquisa das representações sociais, das atas de reuniões da coordenação dos projetos de extensão que faz o balanço periódico das decisões e ações (gravadas em áudio) e de conversas da equipe registradas no Whatsapp e ii) inquérito por questionário e entrevistas (serão apresentados em outro artigo).

A análise dos dados foi pautada na análise do discurso e na identificação dos núcleos central e periféricos das RS. Vale dizer que esta pesquisa não visa mensurar ou julgar as representações identificadas, mas compreender como são originadas e como elas emergem no discurso dos diferentes agentes. Além disso, segundo Silva (2011), as RS constroem-se, disseminam-se nos grupos através da interação, por isso a sua importância para o entendimento do modo pelo qual os sujeitos/grupo se apropriam, aceitam, adotam ou optam por uma determinada postura de/no trabalho.

\section{RESUlTAdOS E DISCUSSÃo}

No quadro 2 apresentam-se os resultados preliminares das representações sociais sobre a articulação reveladas em cada contexto de extensão articulador identificado por articula eventos, articula escolas, articula formação e articula cursinhos.

Quadro 2: Representações sociais e episódios relevantes

\begin{tabular}{|l|l|}
\hline \multicolumn{1}{|c|}{ Representações sociais } & \multicolumn{1}{c|}{ Episódios relevantes } \\
\hline $\begin{array}{l}\text { Agente externo como mani- } \\
\text { pulador ou ameaçador }\end{array}$ & $\begin{array}{l}\text { Articula eventos: a articula e outro docente universitário (ambos } \\
\text { da ADUNIFESP/Associação de Docentes da UNIFESP- sindica- } \\
\text { to) tentaram participar de um evento do movimento estudantil, } \\
\text { mas perceberam que os estudantes estavam receosos em serem } \\
\text { manipulados pelo movimento docente. } \\
\text { Articula eventos: evento Petróleo e a soberania nacional organi- } \\
\text { zado pela universidade e ex-prefeito da cidade ligado a partido } \\
\text { político contou com reduzido público de acadêmicos, sendo a } \\
\text { maioria do público ligada a sindicatos e/ou escolas e/ou partido } \\
\text { político. }\end{array}$ \\
\hline $\begin{array}{l}\text { Agente externo como parti- } \\
\text { cipante pontual estratégico } \\
\text { (defendem mesma posição) }\end{array}$ & $\begin{array}{l}\text { Articula eventos: participação de reunião fechada sobre o Plano } \\
\text { Municipal de Educação na Secretaria municipal de Diadema. }\end{array}$ \\
\hline
\end{tabular}




\begin{tabular}{|c|c|}
\hline Representações sociais & Episódios relevantes \\
\hline $\begin{array}{l}\text { Agente externo como partici- } \\
\text { pante passivo (por exemplo, } \\
\text { ouvinte e não palestrante) }\end{array}$ & $\begin{array}{l}\text { Articula eventos: no II Simpósio de Educação em Diadema } \\
\text { (outubro/2015), a UNIFESP não foi convidada a participar nem } \\
\text { como palestrante, nem como público-ouvinte. A articula partici- } \\
\text { pou porque foi informalmente convidada pela diretora da Escola } \\
\text { Municipal Luiz Gonzaga. } \\
\text { Articula eventos: participação de dois docentes da UNIFESP- } \\
\text { Diadema (incluindo a articula) na discussão do Plano Municipal } \\
\text { de Educação junto à comunidade escolar, na Câmara de Verea- } \\
\text { dores. } \\
\text { Articula eventos: participação informal da articula na reunião da } \\
\text { secretária municipal de Diadema com todos os diretores da Edu- } \\
\text { cação de Jovens e Adultos do Município de Diadema. } \\
\text { Articula formação: relato de uma das diretoras "os estagiários } \\
\text { que ficam sentados no fundo da sala de aula, no celular ou sem } \\
\text { fazer nada, não são bem-vindos na escola". }\end{array}$ \\
\hline $\begin{array}{l}\text { Agente externo como partici- } \\
\text { pante ativo e colaborativo }\end{array}$ & $\begin{array}{l}\text { Articula eventos: UNIFESP tem convidado as comunidades } \\
\text { escolares e gestora-educacional a participar de seus eventos, } \\
\text { por exemplo, na Semana Científica e Cultural de Diadema (SC- } \\
\text { CUD), Congressos acadêmicos, debate e rodas de conversas, } \\
\text { inclusivamente como oradores. } \\
\text { Articula formação: participação de um professor universitário da } \\
\text { área das Ciências Ambientais no ATPC da escola sobre Sustenta- } \\
\text { bilidade (projeto da escola que seria apresentado à comunidade } \\
\text { escolar). } \\
\text { Articula escolas: Participação de duas professoras dos Institutos } \\
\text { de Educação Carmela Dutra e Clelia Nancy em disciplinas da } \\
\text { Licenciatura em Física da UERJ. } \\
\text { Articula formação: participação ativa dos acadêmicos no campo } \\
\text { escolar de estágio supervisionado nos ATPCs de formação, nas } \\
\text { reuniões e atividades das escolas. } \\
\text { Articula formação: participação ativa dos práticos na universi- } \\
\text { dade no âmbito do estágio supervisionado (por exemplo, partici- } \\
\text { pando de debates nas aulas ministradas na UNIFESP). } \\
\text { Articula formação: escolas solicitam que os estagiários partici- } \\
\text { pem de alguma atividade extracurricular na escola. } \\
\text { Articula escolas: negociação com a comunidade escolar de Dia- } \\
\text { dema no período de ocupações das escolas pelos estudantes da } \\
\text { rede estadual. } \\
\text { Articula escolas: discussão sobre a Base Nacional Comum Cur- } \\
\text { ricular (BNCC) no portal do MEC.com os professores na Escola } \\
\text { Estadual de Diadema e Escola Municipal Luiz Gonzaga e envio } \\
\text { de propostas ao MEC. }\end{array}$ \\
\hline $\begin{array}{l}\text { Agente externo com reduzida } \\
\text { participação por receio de } \\
\text { desvio da função do pesqui- } \\
\text { sador ou do estagiário }\end{array}$ & $\begin{array}{l}\text { Articula formação: Alguns acadêmicos consideram desvio de } \\
\text { função a nossa participação no ATPC de formação porque deso- } \\
\text { brigava a coordenadora pedagógica de exercer o seu papel. } \\
\text { Articula formação: alguns docentes recusam-se a "pisar nas es- } \\
\text { colas"; "os estagiários devem negociar o próprio estágio" (frases } \\
\text { ditas por uma orientadora de estágio). } \\
\text { Articula formação: algumas escolas querem que os alunos mi- } \\
\text { nistrem aulas (estagiário só pode realizar regência sob a supervi- } \\
\text { são de um professor e não o substituir em caso de falta). }\end{array}$ \\
\hline
\end{tabular}




\begin{tabular}{|c|c|}
\hline Representações sociais & Episódios relevantes \\
\hline $\begin{array}{l}\text { Valorização do contributo da } \\
\text { pesquisa pelos práticos }\end{array}$ & $\begin{array}{l}\text { Articula formação: elevada satisfação por parte da coordenação } \\
\text { pedagógica e professores. Estamos com a agenda praticamente } \\
\text { preenchida neste semestre. Os temas solicitados são BNCC, } \\
\text { currículo do EJA, Sustentabilidade, Educação Matemática nos } \\
\text { anos iniciais. } \\
\text { Articula escolas: professores envolvidos nas primeiras edições } \\
\text { do PIBIC-EM permaneceram nos projetos e querem fazer mes- } \\
\text { trados na universidade. }\end{array}$ \\
\hline $\begin{array}{l}\text { Valorização do contributo dos } \\
\text { práticos (escolas e gestores } \\
\text { do poder público educacio- } \\
\text { nal) na formação dos profes- } \\
\text { sores }\end{array}$ & $\begin{array}{l}\text { Articula formação: um professor da escola e uma gestora da } \\
\text { secretaria municipal de educação (presidente do conselho muni- } \\
\text { cipal de educação) foram júri na banca de trabalho de conclusão } \\
\text { de curso (TCC) de um licenciando da UNIFESP. } \\
\text { Articula escolas: atualmente somos três docentes da UNIFESP } \\
\text { na equipe Articul@ções orientando projetos de iniciação científi- } \\
\text { ca com as escolas. } \\
\text { Articula formação: os professores das escolas estão se oferecen- } \\
\text { do para atuarem na supervisão de estágio porque entenderam o } \\
\text { seu fundamental papel na formação dos futuros-professores. }\end{array}$ \\
\hline $\begin{array}{l}\text { Colaboração na Formação de } \\
\text { Professores }\end{array}$ & $\begin{array}{l}\text { Articula escolas: Os professores das duas instituições de ensino } \\
\text { médio - Institutos de Educação Carmela Dutra e Clélia Nanci } \\
\text { interagem entre eles e com a UERJ. }\end{array}$ \\
\hline $\begin{array}{l}\text { Interdisciplinaridade como } \\
\text { forma de superação de barrei- } \\
\text { ras ontológicas }\end{array}$ & $\begin{array}{l}\text { Articula eventos: projeto de extensão: A diversidade cultural } \\
\text { brasileira: a física na sua formação. }\end{array}$ \\
\hline $\begin{array}{l}\text { Competitividade dos cursi- } \\
\text { nhos }\end{array}$ & $\begin{array}{l}\text { Articula cursinhos: alguns voluntários do cursinho Natec (apoia- } \\
\text { do pelo articula cursinhos) migraram para o emancipa por ser } \\
\text { ligada a um movimento social. }\end{array}$ \\
\hline $\begin{array}{l}\text { Relações hierárquicas entre } \\
\text { pesquisadores e práticos }\end{array}$ & $\begin{array}{l}\text { Articula cursinhos: a pesquisadora-docente da universidade } \\
\text { continua sendo vista como coordenadora principal do cursinho } \\
\text { pelos professores das escolas que são os coordenadores, mas o } \\
\text { seu papel é de articuladora e apoiadora dos vários cursinhos da } \\
\text { cidade. }\end{array}$ \\
\hline Colegialidade e cooperação & $\begin{array}{l}\text { Articula cursinhos: os participantes dos diferentes cursinhos } \\
\text { conseguiram permutar alguns voluntários. } \\
\text { Articula cursinhos: os alunos da UNIFESP que atuam no cursi- } \\
\text { nho da Rede Emancipa solicitam pontualmente as salas de aula } \\
\text { da UNIFESP para o outro cursinho integral que funciona na } \\
\text { UNIFESP (cooperação entre os cursinhos). }\end{array}$ \\
\hline
\end{tabular}

Fonte: Autores (2018).

A proposta do Articul@ções na formação de professores é potenciar a relação triádica (licenciando ou estagiário - pesquisador ou orientador da Universidade - professor ou supervisor da Escola), ou seja, tornar os agentes mais ativos e colaborativos nos vários contextos e não meramente como visitantes e observadores passivos. Entretanto, as RS apontam a existência de passividade e reduzida participação dos agentes externos por receio de desvio da função do pesquisador ou do estagiário. O Professor-Supervisor da Escola tem um "trabalho extra" de supervisão que necessita ser reconhecido pelas políticas públicas, avaliado pelas instituições envolvidas, regulamentado e devidamente creditado (progressão 
da carreira) para a melhoria do próprio processo de supervisão (CRUZ, PASSOS e KAWAMURA, 2015). A valorização dos práticos (professores e gestores) pelos acadêmicos e dos acadêmicos pelos práticos também foi revelada nas RS e pode ter contribuído para o aumento da cooperação, colaboração em vários cenários (cursinhos, eventos e formação) e redução da competição. Algumas hipóteses referidas no quadro 1 permanecem inalteradas pela ausência de novos indicadores ou de dados que possibilitem a sua reformulação porque alguns projetos de extensão avançaram mais que outros. $\mathrm{O}$ quadro 3 três apresenta as novas hipóteses.

Quadro 3: Projetos e novas hipóteses

\begin{tabular}{|l|l|}
\hline \multicolumn{1}{|c|}{ Projetos } & \multicolumn{1}{c|}{ Novas hipóteses } \\
\hline $\begin{array}{l}\text { Articula } \\
\text { eventos }\end{array}$ & $\begin{array}{l}\text { Alguns eventos sectários e concorrentes impedem a articulação. Os agentes ex- } \\
\text { ternos dos eventos articulados são rotulados apenas pelas posiços políticas e/ou } \\
\text { partidárias e não por pertencer a um segmento (escolas, comunidade em geral etc.) } \\
\text { enquanto os agentes internos são vistos apenas pelo segmento a que pertencem. }\end{array}$ \\
\hline $\begin{array}{l}\text { Articula } \\
\text { cursinhos } \\
\text { populares }\end{array}$ & $\begin{array}{l}\text { Os cursinhos populares coordenados por professores das escolas e que são apoiados } \\
\text { pela universidade ou funcionam no seu espaço com o apoio de graduandos apre- } \\
\text { sentam a identidade universitária pela dificuldade de rompimento com as relações } \\
\text { hierárquicas e apropriação pelos agentes externos. }\end{array}$ \\
\hline
\end{tabular}

Fonte: Autores (2018).

\section{CONSIDERaÇões FINAIS}

Este trabalho apresentou os resultados preliminares da etapa principal de uma pesquisa etnográfica realizada pela equipe. O tempo dispendido para a conquista da confiança do grupo estudo levou aproximadamente UM ano. Os articuladores, envolvidos na pesquisa das representações sociais, procuraram partilhar a dinâmica acadêmica (desafios, avanços e dificuldades) e ter uma atitude de empatia enfatizando sempre a importância de não se fazer julgamentos sobre as práticas observadas nos vários contextos. A opção por apresentar um trabalho com todos os segmentos (eventos, formação, escolas e cursinhos) deve-se à necessidade de manter o fio condutor do programa evidenciado quer na articulação do conhecimento acadêmico e conhecimento prático dos mais experientes (professores das escolas, sociedade, integrantes dos movimentos sociais, entre outros), quer na aproximação dos agentes da educação básica (gestores e professores) e ensino superior (gestores e docentes) voltado para um objetivo comum (aproximação da universidade-escolas-poder público educacional-sociedade).

Apesar de todos defenderem a importância de se promover a aproximação/interação entre universidades, escolas e sociedade (comunidade local, movimentos sociais, etc.) e poder público educacional (secretarias municipais, diretorias de ensino, conselhos, fóruns etc.), o discurso nem sempre se concretizou em práticas articuladoras (PARDAL et al., 2011). Podemos dizer que houve uma evolução nas representações mais periféricas, mesmo que o núcleo central tenha tido uma evolução mais lenta preservando a identidade 
do segmento e guardando ainda vestígios de uma antiga representação. Relativamente às ações (produções de linguagem tomadas em sua dimensão individual) e as nossas atividades articuladoras gerais e específicas na Educação em Ciências e Formação de Professores de Ciências (ações do ponto de vista da coletividade) são norteadas por sentidos que variam de acordo com o grupo social ao qual pertencemos (no caso, ao novo grupo dos articuladores versus grupo original ao qual pertencemos) e com os processos interpretativos das experiências interiorizadas que demandam certamente de tempo. Espera-se que este trabalho possa auxiliar os pesquisadores e práticos a refletirem sobre a importância de, por um lado, romperem com as práticas existentes que setorizam as atividades educacionais e culturais (por ex., eventos, cursos, formação, pesquisa e cursinhos populares) nas instituições, não agregando a comunidade local e, por outro, motivar as comunidades (acadêmica, escolar e gestora-educacional) e a sociedade em geral a unirem-se na construção de pontes interinstitucionais e na articulação dos conhecimentos, saberes e experiências.

\section{REFERÊNCIAS}

BRAZ DA SILVA, Alcina Maria Testa. Representações Sociais: uma contraproposta ao estudos das concepções alternativas no ensino de Física. Tese de Doutoramento em Educação, Universidade Federal do Rio de Janeiro, 1998.

COSTA, Nilza. A Investigação Educacional e o seu impacte nas práticas educativas: $\mathbf{O}$ caso da Investigação em Didática das Ciências. Lição Síntese das Provas de Agregação não publicada (Educação). Universidade de Aveiro, 2003.

CRUZ, Eliane. Da Avaliação do Impacte à Articulação da Investigação $\leftrightarrow$ Práticas - O caso da Articulação na Formação Didáctica Pós-Graduada de Professores de Ciências e desafios futuros. Tese de Doutoramento em Didáctica e Formação, Universidade de Aveiro, Portugal. Disponível em: http://ria.ua.pt/handle/10773/10993, 2012.

CRUZ, Eliane; FIRMINO, Ana Maria Firmino; LOPES, Joaquim Bernardino; COSTA, Nilza. Programa Articul@ções "Pesquisa - Práticas" - Etapa Exploração do estudo etnográfico. In: Actas do XXI Simpósio Nacional de Ensino de Física - SNEF 2017- Tema "A Física e o Cidadão Contemporâneo" - São Paulo-SP, 23 a 27 de janeiro de 2017 na Universidade de São Paulo em São Carlos. Editora Sociedade Brasileira de Física/SBF, 2017a.

CRUZ, Eliane; FIRMINO, Ana Maria Firmino; LOPES, Joaquim Bernardino; COSTA, Nilza. ProgramaArticul@ções Pesquisa-Práticas - Ir ou não ir à Escola, eis a questão. In: Actas do XI Encontro Nacional de Pesquisa em Educação em Ciências - XI ENPEC (ISSN 1809-5100). Tema "20 anos de ABRAPEC: Memórias de conquistas e movimentos de resistência". Florianópolis - Santa Catarina - 03 a 06 de julho de 2017. Associação Brasileira de Pesquisa em Educação em Ciências/ABRAPEC, $2017 \mathrm{~b}$. 
CRUZ, Eliane; LOPES, Joaquim Bernardino; COSTA, Nilza. "Avaliação formativa das aprendizagens e feedback na Formação Pós-Graduada de Professores em Portugal articulando a investigação e práticas de formação". Revista Indagatio Didactica (ISSN: 1647-3582) do Centro de Investigação em Didática e Tecnologia na Formação de Formadores (CIDTFF) da Universidade de Aveiro - Aveiro - Portugal, v. 7, n. 1, 2015.

CRUZ, Eliane; PASSOS, Roberto; KAWAMURA, Maria Regina. Relações entre as pesquisas educacionais e suas implicações para as práticas - investigando possíveis indicadores. In: Actas do X Encontro Nacional de Pesquisa em Educação em Ciências - X ENPEC, Águas de Lindóia, SP, 24 a 27 de novembro de 2015. Associação Brasileira de Pesquisa em Educação em Ciências/ABRAPEC, 2015.

CRUZ, Eliane; POMBO, Lúcia; COSTA, Nilza. Dez anos (1997-2007) de evolução do impacte da Formação Pós-Graduada nas Práticas de Professores em Portugal. RBPEC/ Revista Brasileira de Pesquisa em Educação em Ciências, v. 8, n. 1, 2008.

GRAVANI, Maria N. Academics and practitioners: Partners in generating knowledge or citizens of two different worlds? Teaching and Teacher Education, v. 24, n. 3, p. 649$659,2008$.

HAMMERSLEY, Martyn. Educational Research and Teaching: a response to David Hargreaves' TTA lecture. British Educational Research Journal, v. 23, n. 2, p. 141- 161, 1997.

MCINTYRE, Donald. Bridging the gap between research and practice. Cambridge Journal of Education, v. 35, n. 3, p. 357-382, 2005.

MOSCOVICI, Serge. Representações sociais: investigação em psicologia social. Tradução de Pedrinho A. Guareschi. Petrópolis: Vozes, 2007.

NERF - National Education Research Forum. The Impact of Educational Research on Policy and Practice. Sub-group of NERF Report. Disponível em: www.nerf-uk.org/ documents, 2000.

OLIVEIRA, Amurabi. Algumas pistas (e armadilhas) na utilização da Etnografia na Educação, Educação em Foco, v. 16, n. 22, p. 163-183, 2003.

PARDAL, Luís A., GONÇALVES, Manuela; MARTINS, Antônio; NETO-MENDES, Antônio; PEDRO, Ana P. Trabalho docente: Representações e construção de identidade profissional. Aveiro: Universidade de Aveiro, 2011. 
SANTOS, Maria de Fátima de Souza; MORAIS, Edclécia Reino Carneiro; NETO, Manoel de Lima Acioli. A Produção Científica em Representações Sociais: Análise de Dissertações e Teses Produzidas em Pernambuco, PSICO, Porto Alegre, PUCRS, v. 43, n. 2, p. 200-207, 2012.

SILVA, Jânio Almeida. Representações Sociais de ensino: um estudo etnográfico no campo da educação especial. Dissertação de Mestrado em Letras, Pontifícia Universidade Católica de Minas Gerais, Belo Horizonte, 2011.

Dados dos Autores

Eliane de Souza Cruz

Doutora em Didática e Formação de Professores pela Universidade de Aveiro. Portugal. Professora da Universidade Federal de São Paulo. Diadema. São Paulo/SP- Brasil. ecruznovo@gmail.com

Giovano Candiani

Pós-Doutor em Sustentabilidade pela Universidade de São Paulo. São Paulo/SP - Brasil. Professor

na Universidade Federal de São Paulo. Diadema/SP - Brasil. giovanocandiani@gmail.com

JoAquim Bernardino Lopes

$\mathrm{PhD}$ and Aggregation in Physics Education. Professor Doutor no Departamento de Física. Universidade de Trás-os-Montes e Alto. Portugal. blopes@utad.pt

\section{Nilza Costa}

Full Professor at the Department of Education and Psychology of the University of Aveiro. Portugal. Professora do Departamento de Educação e Psicologia na Universidade de Aveiro. Portugal.nilzacosta@ua.pt

\section{Alcina Maria Testa Braz da Silva}

Doutora em Educação pela Universidade Federal do Rio de Janeiro/ FE-UFRJ. Professora no Centro Federal de Educação Tecnológica Celso Suckow da Fonseca. Rio de Janeiro/ RJ-Brasil. alcina.silva@ifrj.edu.br

\section{Glória Regina Pessôa Campello Queiroz}

Doutora em Educação pela Pontifícia Universidade Católica do Rio de Janeiro. Rio de Janeiro/RJ- Brasil. Professora na Universidade do Estado do Rio de Janeiro. Rio de Janeiro/ RJ- Brasil. gloriapcq@gmail.com

Submetido em: 12-12-2018

Aceito em: 15-3-2019 